University of Nebraska - Lincoln

DigitalCommons@University of Nebraska - Lincoln

Michigan Bovine Tuberculosis Bibliography and

Database

Wildlife Disease and Zoonotics

2007

\title{
Coyotes as Sentinels for Monitoring Bovine Tuberculosis Prevalence in White-Tailed Deer
}

\author{
Todd Atwood \\ USDA/APHIS/WS National Wildlife Research Center
}

Kurt C. Vercauteren

USDA/APHIS/WS National Wildlife Research Center, kurt.c.vercauteren@usda.gov

Thomas Deliberto

USDA/APHIS/WS National Wildlife Research Center, Thomas.J.DeLibertot@aphis.usda.gov

Holly Smith

USDA/APHIS/WS National Wildlife Research Center

Justin Stevenson

USDA/APHIS/WS National Wildlife Research Center

Follow this and additional works at: https://digitalcommons.unl.edu/michbovinetb

Part of the Veterinary Medicine Commons

Atwood, Todd; Vercauteren, Kurt C.; Deliberto, Thomas; Smith, Holly; and Stevenson, Justin, "Coyotes as Sentinels for Monitoring Bovine Tuberculosis Prevalence in White-Tailed Deer" (2007). Michigan Bovine Tuberculosis Bibliography and Database. 5.

https://digitalcommons.unl.edu/michbovinetb/5

This Article is brought to you for free and open access by the Wildlife Disease and Zoonotics at DigitalCommons@University of Nebraska - Lincoln. It has been accepted for inclusion in Michigan Bovine Tuberculosis Bibliography and Database by an authorized administrator of DigitalCommons@University of Nebraska - Lincoln. 


\title{
Coyotes as Sentinels for Monitoring Bovine Tuberculosis Prevalence in White-Tailed Deer
}

\author{
TODD C. ATWOOD, United States Department of Agriculture/Animal and Plant Health Inspection Service/Wildife Services/National Wildlife Research \\ Center, 4101 LaPorte Avenue, Fort Collins, CO 80521, USA \\ KURT C. VERCAUTEREN, ${ }^{\mathbf{1}}$ United States Department of Agriculture/Animal and Plant Health Inspection Service/Wildlife Services/National Wildife \\ Research Center, 4101 LaPorte Avenue, Fort Collins, CO 80521, USA \\ THOMAS J. DELIBERTO, United States Department of Agriculture/Animal and Plant Health Inspection Service/Wildlife Services/National Wildife \\ Research Center, 4101 LaPorte Avenue, Fort Collins, CO 80521, USA \\ HOLLY J. SMITH, United States Department of Agriculture/Animal and Plant Health Inspection Service/Wildlife Services/National Wildife Research \\ Center, 4101 LaPorte Avenue, Fort Collins, CO 80521, USA \\ JUSTIN S. STEVENSON, United States Department of Agriculture/Animal and Plant Health Inspection Service/Wildlife Services/National Wildlife \\ Research Center, 4101 LaPorte Avenue, Fort Collins, CO 80521, USA
}

\begin{abstract}
Mycobacterium bovis, the causative agent of bovine tuberculosis (bTB), is endemic in free-ranging white-tailed deer (Odocoileus virginianus) in 5 counties (Alcona, Alpena, Montmorency, Oscoda, and Presque Isle) in the northeastern Lower Peninsula of Michigan, USA. The presence of a wildlife reservoir of tuberculosis in Michigan and the incidence of bTB in cattle (Bos taurus) resulted in Michigan losing its bTB accredited-free status. Subsequent wildlife surveillance programs identified relatively high disease prevalence in coyotes (Canis latrans), generating interest in their potential to serve as a sentinel species to detect bTB prevalence in white-tailed deer. Our goal was to develop an empirical basis for generating hypotheses about the spatial epidemiology of bTB infection in coyotes for future surveillance, management, and modeling efforts. Though variation in coyote home-range size may confound attempts to spatially correlate the incidence of disease in the sentinel and host species at a fine scale, overlap zones (OZs) between adjacent coyote home ranges may be the appropriate sample unit for spatially correlating disease prevalence in coyotes and white-tailed deer. Because overlapping home ranges are generally configured around resource rich (e.g., small mammals and white-tailed deer) timber management patches, the $\mathrm{OZ}$ concentrates spatial interaction between adjacent groups in a relatively small area. Furthermore, there is a direct relationship between interaction probabilities and the spatial dispersion of those patches. The latter finding provides a useful metric to incorporate into future efforts to develop spatially explicit models of bTB dynamics. Modeling efforts can then be used as a foundation to predict the epidemiological ramifications of alterations in intensively managed forested landscapes. (JOURNAL OF WILDLIFE MANAGEMENT 71(5):1545-1554; 2007)
\end{abstract}

DOI: $10.2193 / 2006-441$

KEY WORDS bovine tuberculosis, coyote, disease, Mycobacterium bovis, spatial, timber management, white-tailed deer.

Sixty percent of human pathogens are zoonoses and up to $90 \%$ of domestic animal pathogens can infect $>1$ host species (Cleaveland et al. 2001, Taylor et al. 2001). Of the pathogens found to affect humans and wildlife, $13 \%$ are regarded as emerging (e.g., severe acute respiratory syndrome [SARS], human immunodeficiency virus [HIV]) or reemerging (e.g., tuberculosis, west Nile virus, malaria; Woolhouse and Gowtage-Sequeria 2005) and approximately 50\% have a wildlife reservoir (Dobson and Foufopoulos 2001). Appropriately, there is great interest in understanding disease dynamics in wild populations. There is cause to integrate disease and landscape ecology because infectious diseases often emerge from complex ecological communities involving potential hosts interacting over multiple spatial scales. Indeed, several infectious zoonotic diseases (e.g., SARS, $\mathrm{HIV}$, avian influenza) appear to be strongly influenced by anthropogenic activities, including intensive agriculture (Schrag and Wiener 1995), clear-cut forestry (Laurance et al. 1996), and habitat loss and fragmentation (McCallum and Dobson 2002). Such environmental impacts may facilitate pathogen acquisition by species that occur at trophic levels below or above the host community, suggesting that changes in the structure and composition of ecological communities

${ }^{1}$ E-mail: kurt.c.vercauteren@aphis.usda.gov may alter the prevalence of both human and wildlife diseases in unanticipated ways. Human alteration of landscapes, and subsequent perturbations to ecological community structure, has been extensively studied (Wiens et al. 1986, Turner 1989, Crooks and Soule 1999, Theobald 2003). However, substantially less research has been devoted to elucidating the putative link between animal behavior, landscape attributes, and disease prevalence.

Mycobacterium bovis is the causative agent of bovine tuberculosis (bTB) and is capable of infecting a wide array of mammals, including humans (Francis 1958, White and Harris 1995, Bruning-Fann et al. 2001). The main routes of infection are via inhalation of aerosolized bacilli or ingestion of infected tissues. The bacterial pathogen then concentrates in respiratory tissues and the host may exhibit marked behavioral changes before finally succumbing to infection (Cheeseman and Mallinson 1981, Garnett et al. 2005). However, the disease often progresses slowly and clinical symptoms may not be evident until an advanced stage is reached. In 1995, bTB was found to be endemic in free-ranging white-tailed deer (Odocoileus virginianus) in the northeastern lower peninsula of Michigan, USA (Schmitt et al. 1997). Although prevalence was determined to be relatively low $(0.5 \%$; Payeur et al. 2002), the occurrence was cause for concern in that it represented 
the only self-sustaining bTB reservoir in a free-ranging North American cervid population and resulted in Michigan losing its bTB accredited-free status. Subsequently, an extensive multi-species surveillance program determined coyotes (Canis latrans) were likely candidates for bioaccumulation of bTB through feeding on infected deer carcasses (Bruning-Fann et al. 2001, Michigan Department of Natural Resources [MDNR] 2005). Social scavenging (Gese et al. 1996, Atwood 2006), coupled with a high degree of vagility, should increase the likelihood of multiple coyotes ingesting infected tissue from a bTB-infected white-tailed deer. Because of this potential for increased numerical exposure, there is interest in using coyotes as sentinels to detect bTB prevalence in white-tailed deer. To be effective sentinels, coyotes should 1) facilitate detection of disease prevalence with reasonable sampling effort, 2) become infected via direct interaction with the host species, and 3) manifest relatively constrained space use so spatial correlation between the incidence of disease in both the sentinel and host species is high. Thus, identifying intrinsic and extrinsic factors that may mediate bTB transmission to and among coyotes is essential.

Contact rate, through its effects on transmission, is one of the most important parameters determining the dynamics of wildlife diseases (McCallum et al. 2001). Primary intrinsic factors exacerbating contact rates in coyotes are predation and scavenging of infected white-tailed deer and social interaction with conspecifics. In territorial carnivores, social contact is facilitated by 1 ) home range overlap, 2) extent of utilization of the overlap zone (OZ), and 3) the level of interaction that takes place within the $\mathrm{OZ}$ (Atwood and Weeks 2003). Contact is extensive within carnivore social groups (Gese et al. 1996, Holekamp et al. 1997) and, not surprisingly, disease prevalence often is correspondingly high (Rhodes et al. 1998, Tuyttens et al. 2000). However, there is a paucity of data examining social contact as a mechanism of disease transmission between social groups, despite supporting circumstantial evidence (Cully and Williams 2001, Altizer et al. 2003). The likelihood and nature of contact between groups can be highly variable and influenced by additional factors such as kinship (Holekamp et al. 1997), dispersal (Gese et al. 1996), agonistic behavior (e.g., intraspecific competition; de Villiers et al. 2003, Atwood 2006), and group stability (Delahay et al. 2000, Woodroffe et al. 2006). Thus, the spatial distribution of infected individuals may either occur as primary clusters comprised of discrete social groups or as meta-clusters comprised of interacting (either spatially or behaviorally) primary clusters. This can be determined by employing an approach linking disease prevalence to space and resource use.

Coyote spatial and social organizations provide 2 potential mechanisms of disease acquisition: transmission within or among social groups (Smith et al. 1995). At each scale of transmission it is possible that discrepant epidemiological and ecological processes may be influential. At a fine scale, intrinsic factors (i.e., coyote social behaviors) are likely to interact with the spatial arrangement of bTB-infected white-tailed deer to determine disease prevalence in coyotes. If little social interaction occurs between adjacent groups, infection clusters should be discrete and correlated to the distribution of infected deer. As the scale coarsens, it is likely that intrinsic and extrinsic factors (e.g., landscape attributes; Smith et al. 2002) interact to determine the spatial distribution of infection in coyotes. At a landscape scale, habitat patch juxtaposition can modify the strength of intraspecific competition in coyotes through mediating contest competition for critical resource patches, thereby facilitating spatio-temporal interaction (Atwood and Weeks 2003, Atwood et al. 2004). If landscape attributes function to influence disease infection in coyotes, then landscape correlates should exist in the spatial aggregation of infection clusters. Spatial attributes and heterogeneity relative to disease prevalence can then be assessed within a regression modeling framework (Pfeiffer and Hugh-Jones 2002). This may be a particularly powerful approach when coupled with behavioral covariates and used to predict the likelihood of disease presence over larger scales.

We investigated coyote spatial and behavioral ecology relative to bTB prevalence with the aim of evaluating coyotes as sentinels to monitor bTB occurrence in whitetailed deer. Few data have been published relating landscape attributes and social interactions with the spatial epidemiology of wildlife diseases (Mollison and Levin 1995, Hess et al. 2002, Smith et al. 2002, Conner and Miller 2004) and no data have been published on these effects in canids. We sought to develop an empirical basis for generating hypotheses about the spatial epidemiology of bTB infection in coyotes for future surveillance, management, and modeling efforts. We used radiotelemetry location and georeferenced bTB surveillance data to describe spatial relationships between coyote ecology and bTB prevalence. Specifically, our objectives were to examine: 1) general spatial ecology of coyotes relative to bTB prevalence, 2) the potential for transmission within and among social groups, and 3 ) the potential for behavior and landscape attributes to modulate the spatial distribution of bTB-infected coyotes.

\section{STUDY AREA}

We conducted our research in a $717-\mathrm{km}^{2}$ area that encompassed portions of Oscoda and Crawford counties in Michigan's lower peninsula (Fig. 1). Our study area was physiographically diverse, with moraine uplands dominated by forests of jack pine (Pinus banksiana), white pine (P. alba), oak (Quercus spp.), and maple (Acer spp.). Wetland ephemera were common in lowlands, where dominant vegetation was tag alder (Alnus rugosa) and white cedar (Thuja occidentalis). Conifer and mixed (conifer and deciduous) forests comprised $62 \%$ of the area; timber cuts, herbaceous old-fields, deciduous forest, and wetlands comprised $11 \%, 9 \%, 7 \%$, and $6 \%$, respectively. Human development and row-crop agriculture comprised the remaining $5 \%$ of the area. Portions of our study site fell within Kirtland's warbler (Dendroica kirtlandii) management areas. Management areas were jack pine barrens logged, 


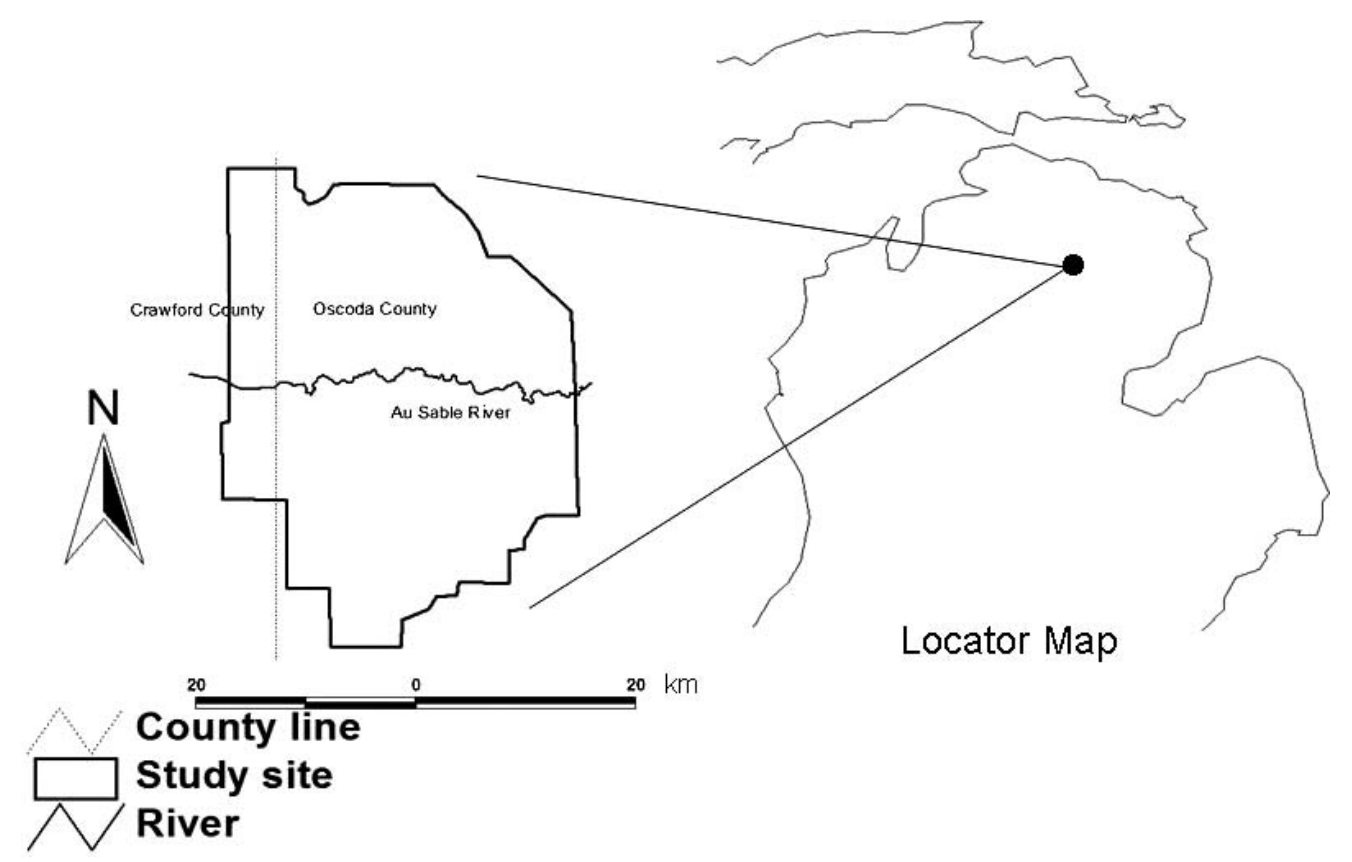

Figure 1. Coyote study area in Crawford and Oscoda counties in the northeastern Lower Peninsula of Michigan, USA, 2001-2003.

burned, seeded, and replanted on a 50-year rotation. Annual precipitation typically ranged from $71 \mathrm{~cm}$ to $91 \mathrm{~cm}$, the bulk of which occurred as snowfall. Mean yearly summer and winter temperatures were $21^{\circ} \mathrm{C}$ and $-10^{\circ} \mathrm{C}$, respectively.

\section{METHODS}

We captured coyotes using padded foothold traps from September through March 2001-2003. We immobilized coyotes with an intramuscular injection of ketamine hydrochloride $(100 \mathrm{mg} / \mathrm{kg})$ and acepromazine $(1 \mathrm{mg} / \mathrm{kg})$, collected morphometric data, and attached eartags and radiocollars (Advanced Telemetry Systems, Isanti, MN). We extracted a premolar for cementum annuli determination of age (Matson's Laboratory, LLC, Milltown, MT). We located radiocollared coyotes via ground-based triangulation using portable receivers and handheld 4-element antennas. We used aerial telemetry to search for missing individuals when we could not locate them from the ground.

We structured our telemetry sampling design so that we collected 4 locations per coyote per week over a diel interval partitioned into 4 time periods $(0600-1200 \mathrm{hr}, 1200-1800$ hr, 1800-2400 hr, 2400-0600 hr). Thus, within a week, we collected 4 point locations from 4 separate time periods for each coyote. This sampling strategy provided data on space use free of bias from diel activity patterns. We converted differentially corrected triangulation data to point locations using the maximum-likelihood estimator computed by the software Locate II (Pacer Computer Software, Truro, NS, Canada). We calculated true bearings for a set of reference transmitters following White and Garrott (1990), and we used the standard deviation of bearing error (Lee et al. 1985) to calculate $95 \%$ confidence ellipses. Because we needed relatively fine-resolution radiotelemetry data for spatial analyses, we censored bearings from data collected over $>15$ minutes and having an error ellipse $>0.50$ ha. We determined home-range ( $95 \%$ contour) and core-area $(65 \%$ contour; Shivik and Gese 2000) sizes using the fixed-kernel (FK) option in the Animal Movement extension in ArcView 3.2. Fixed-kernel estimators allow the identification of disjunct areas of activity (Seaman et al. 1999), a particularly important consideration in intensively managed landscapes.

We used georeferenced data from ongoing carnivore and white-tailed deer bTB surveillance programs to estimate local bTB prevalence in our study area. Under the program (MDNR 2005) sampled hunter- and road-killed deer and carnivores were classified as bTB+ (infected) or bTB(uninfected) based on results of histopathological examination of the parotid, mandibular, medial and lateral retropharyngeal, and bronchial and mediastinal lymph nodes (Schmitt et al. 1997, Bruning-Fann et al. 2001). All histology screenings were conducted at the Animal Health Diagnostic Laboratory and the National Veterinary Services Laboratory (Ames, IA). Portions of lymph node tissue from animals suspected to be $\mathrm{bTB}+$ were then cultured for mycobacterial isolation and identification. We used point locations from recovered $\mathrm{bTB}+$ animals to generate a $90 \%$ minimum convex polygon (MCP) to estimate the areal distribution of $\mathrm{bTB}$ prevalence for our study area. We used the $90 \% \mathrm{MCP}$ as a conservative estimate of the areal distribution of bTB in the event that extreme movements by infected coyotes biased the delineation of the polygon boundaries. We characterized home ranges, core areas, and overlap zones that fell at least partially within the $\mathrm{bTB}$ prevalence polygon as $\mathrm{bTB}+$ for spatial analyses.

\section{Spatial Analysis}

We grouped radiolocations into 2 seasons (autumn-winter: 16 Sep-15 Apr; spring-summer: 16 Apr-15 Sep) based on relevant biological and behavioral events. In autumn and winter, white-tailed deer hunting and harsh winter 
conditions should increase the likelihood of coyotes directly acquiring bTB infection through contact with $\mathrm{bTB}+$ deer and hunter-provisioned viscera. Additionally, coyote agonistic behavior associated with dispersal and pair formationbonding (Gese et al. 1996) should elevate the potential for indirectly acquiring bTB infection through intra- and intergroup contact (Rogers et al. 1998). In spring and summer, the potential for secondary infection, via social contact between adjacent coyote groups, should decrease as home ranges contract concomitant with the demands of gestation and pup-rearing. Moreover, declines in carrion resources should reduce the likelihood of primary infection through scavenging behavior. We classified spatially overlapping coyotes into pair (M-F, M-M, F-F) and group types (family or adjacent) based on capture (sex and age) and radiotelemetry data. As in Atwood et al. (2004), we used a Geographic Information System (GIS) to examine point locations of M-F pairs in April and May to detect spatial patterns indicating localization around den sites. Because spatial dependence in breeding pairs is elevated and could bias estimates of overlap, we censored male-female pairs when localized pup-rearing behavior was evident (Atwood and Weeks 2003). We further classified overlapping pairs as belonging to either family groups or to adjacent groups based on considerations similar to the above.

We quantified spatial overlap of coyote $95 \%$ FK seasonal home-ranges using theme-overlay routines in ArcView. We calculated percent overlap as:

$$
\begin{gathered}
\text { overlap }=\left[\left(\operatorname{area}_{\alpha \beta} / \text { home range }_{\alpha}\right)\right. \\
\left.\left(\operatorname{area}_{\alpha \beta} / \text { home } \operatorname{range}_{\beta}\right)\right]^{0.5}
\end{gathered}
$$

where $\operatorname{area}_{\alpha \beta}$ is the overlap area common to home ranges $\alpha$ and $\beta$, and home range $e_{\alpha}$ and home range $e_{\beta}$ are the respective individual home ranges. We further used overlay routines to quantify the distribution of coyote point-locations relative to habitat type within coyote home ranges, core areas, and $\mathrm{OZs}$, and to determine the availability of habitat types on the landscape. Following Conner and Miller (2004), we estimated a potential interaction probability $\left(P_{i j}\right)$ for each spatially overlapping sample unit as

$$
P_{i j}=\sum R_{i j k} / n_{i}
$$

where $R_{i j k}$ is an indicator variable that is one for each $k$ location of a coyote from home range $i$ found within the home range of $j$ and a zero otherwise, and $n_{i}$ is the total number of locations for all coyotes in home range $i$. We used resource selection functions (RSF; Manly et al. 2002) to determine use versus availability of landscape attributes for home-ranges, core-areas, and OZs of coyotes relative to $\mathrm{bTB}$ prevalence. Resource selection functions were estimated via logistic regression using the following formula:

$$
\mathrm{W} *=\operatorname{ext}\left(\beta_{1} X_{1}+\beta_{2} X_{2}+\cdots \beta_{p} X_{p}\right)
$$

where $\mathrm{W} *$ is an index of the probability of use of a given site and $\beta_{1}$ is the selection coefficient of resource variable $X_{1}$ (Manly et al. 2002). We determined use versus availability by comparing point locations from radiotelemetry sampling to equal numbers of random locations. For all RSF models, we checked continuous variables for conformity to linearity using the quartile method (Hosmer and Lemeshow 2000). We ensured final model fit by testing with the Hosmer and Lemeshow goodness-of-fit statistic (Hosmer and Lemeshow 2000).

We examined variation in home-range and core-area size using unbalanced factorial analysis of variance (Zar 1999) with sex, season, and bTB prevalence (positive or negative) as main effects. Area values were natural logarithm-transformed to meet assumptions of homoscedasticity (Zar 1999). We used mean-squared differences (MSD) of nearest-neighbor timber management, wetland, and mixed-forest patches, season, and pair type and group type (family or adjacent) of overlapping coyote pairs as independent variables in general linear models of interaction probabilities $\left(P_{i j}\right)$. We used dummy variable coding for categorical variables (Neter et al. 1996). If we monitored coyote groups over multiple years, we calculated seasonal averages for independent variables used in the analysis so that one data point was generated for each group per season (Atwood and Weeks 2003). We developed 3 model sets: a full set composed of all overlapping pairs, a reduced set with family groups censored from the data set, and a reduced set comprised solely of overlapping adjacent pairs that also partially or completely overlapped the $\mathrm{bTB}+$ zone. We censored breeding pairs from the data set because of their high degree of spatial dependence (Atwood and Weeks 2003). We assembled sets of candidate models based on habitat attributes retained in RSF models and identified in similar modeling efforts (Atwood and Weeks 2003). We assessed homoscedasticity of continuous variables using normal probability plots (Neter et al. 1996). We used Akaike's Information Criterion (AIC; $\mathrm{AIC}_{c}$ for small sample sizes) to select the most parsimonious RSF and multiple regression models (Burnham and Anderson 2002). We calculated Akaike weights $\left(w_{i}\right)$ to aid in the determination of the best model; $w_{i}$ values approximate the probability that a model is the best Kullback-Leibler model (Burnham and Anderson 2002). When model uncertainty arose, we determined the relative likelihood that one model was better than another as $w_{i} / w_{j}$ (Burnham and Anderson 2002). We considered models with $\mathrm{AIC}_{c}$ values $>2.0$ (i.e., $2.0=\Delta_{i}=\mathrm{AIC}_{i}-\min . \mathrm{AIC}$ ) to be significant (Burnham and Anderson 2002). Research and handling protocols were reviewed and approved by Institutional Animal Care and Use Committees at the National Wildlife Research Center.

\section{RESULTS}

We radiocollared 61 coyotes ( $25 \mathrm{~F}, 36 \mathrm{M}), 18$ of which we monitored from capture to the termination of our study or until we confirmed dispersal from our study site. Humans were the primary cause of death for radiocollared coyotes; 31 were killed by hunters or trappers, 3 were killed by vehicle collisions, and 2 were killed in capture operations (i.e., capture myopathy). Five coyotes died from exposure 
Table 1. Relative odds ratios of parameter estimates, standard errors, and corresponding $P$-values for independent variables in resource selection function models for the best Akaike's Information Criterion coyote 95\% fixed-kernel (FK) and 65\% FK seasonal models, Crawford and Oscoda counties, Michigan, USA 2001-2003.

\begin{tabular}{|c|c|c|c|c|c|c|c|}
\hline Model & Conifer & Mixed forest & Deciduous & Timber cut & Wetland & Agriculture & Distance road \\
\hline $95 \%$ FK autumn \& winter & 1.811 & 1.919 & & 1.224 & & & 1.001 \\
\hline $\mathrm{SE}$ & 0.115 & 0.118 & & 0.205 & & & $<0.001$ \\
\hline$P$-value & $<0.001$ & $<0.001$ & & $<0.001$ & & & \\
\hline $95 \%$ FK spring \& summer & 1.482 & 3.243 & 0.676 & 8.850 & 1.544 & & \\
\hline $\mathrm{SE}$ & 0.131 & 0.125 & 0.216 & 0.194 & 0.159 & & \\
\hline$P$-value & 0.003 & $<0.001$ & 0.069 & $<0.001$ & 0.006 & & \\
\hline $65 \%$ FK autumn \& winter & 3.529 & 4.966 & & 6.403 & 1.866 & 2.975 & \\
\hline $\mathrm{SE}$ & 0.167 & 0.166 & & 0.247 & 0.219 & 0.244 & \\
\hline$P$-value & $<0.001$ & $<0.001$ & & $<0.001$ & 0.004 & $<0.001$ & \\
\hline $65 \%$ FK spring $\&$ summer & 2.045 & 3.707 & & 8.432 & 1.467 & 4.083 & \\
\hline $\mathrm{SE}$ & 0.133 & 0.129 & & 0.201 & 0.171 & 0.180 & \\
\hline$P$-value & $<0.001$ & $<0.001$ & & $<0.001$ & 0.024 & $<0.001$ & \\
\hline
\end{tabular}

exacerbated by sarcoptic mange infection and 2 died of unknown causes. During our study, we recovered 6 bTB+ coyotes from our immediate study site and $14 \mathrm{bTB}+$ whitetailed deer (S. Schmitt, MDNR, personal communication) from within Oscoda and Crawford counties. We recovered all bTB + coyotes from the Oscoda County portion of our study area. We collected 5,619 point locations on 48 resident individuals for spatial analyses.

\section{Resource Selection}

Despite some consistency in covariates retained in the best models of resource selection, there were important differences in the use of habitat types relative to season and scale (Table 1). Autumn and winter probability of coyote occurrence within $95 \%$ FK home ranges increased in conifer $(\beta=0.594)$ and mixed forests $(\beta=0.652)$, timber management patches $(\beta=1.014)$, and distance from roads $(\beta=0.001)$. For the spring and summer season, resource selection was similar in that probability of occurrence increased in conifer $(\beta=0.393)$ and mixed forests $(\beta=$ 1.176) and in timber management patches $(\beta=2.180)$. However, in contrast to autumn and winter, probability of occurrence increased in wetlands $(\beta=0.435)$ and decreased in deciduous forest $(\beta=-0.391)$. For $65 \%$ FK core areas, autumn and winter probability of occurrence increased in conifer $(\beta=1.261)$ and mixed forests $(\beta=1.603)$, timber management patches $(\beta=1.857)$, wetlands $(\beta=0.624)$, and pastures $(\beta=1.092)$. Spring and summer $65 \%$ FK resource selection was qualitatively similar in that probability of occurrence increased for the same habitat types (Table 1), however, inspection of odds ratios revealed important differences in the odds of occurrence. For example, the relative odds of coyotes using conifer forests in spring and summer declined by over a third compared to autumn and winter (Table 1). Similarly, coyotes were nearly a fourth as likely to use mixed forest and wetland habitats in spring and summer (Table 1). By contrast, coyotes were a third more likely to use timber management and agriculture patches in spring and summer (Table 1).

Resource selection within OZs differed substantially from selection within home ranges and core areas. In autumn and winter, probability of coyote occurrence in OZs increased in timber management patches $(\beta=0.306)$ and herbaceous old fields $(\beta=1.024)$ decreased in deciduous forest $(\beta=-0.005)$ and increasing distance from roads $(\beta=-0.001$; Table 2$)$. Twenty of $37 \mathrm{OZs}$ fell within the georeferenced bTB+ area, and within these overlap areas probability of coyote occurrence increased in deciduous forest $(\beta=1.083)$, timber management patches $(\beta=0.667)$, herbaceous old field $(\beta=$ $0.558)$, and with distance from roads $(\beta=0.001$; Table 2$)$. In spring and summer, probability of coyote occurrence in OZs increased in wetlands $(\beta=4.115)$, herbaceous old fields ( $\beta=1.444)$, pastures $(\beta=1.588)$, deciduous forest $(\beta=$

Table 2. Relative odds ratios of parameter estimates, standard errors, and corresponding $P$-values for independent variables in coyote resource selection function models for the best Akaike's Information Criterion overlap zone seasonal models, Crawford and Oscoda counties, Michigan, USA $2001-2003$.

\begin{tabular}{|c|c|c|c|c|c|c|c|}
\hline Model & Mixed forest & Deciduous & Timber cut & Wetland & Pasture & Old field & Distance road \\
\hline Autumn \& winter & & 0.955 & 1.357 & & & 2.784 & 1.001 \\
\hline SE & & 0.378 & 0.195 & & & 0.182 & $<0.001$ \\
\hline$P$-value & & 0.004 & 0.006 & & & 0.002 & $<0.001$ \\
\hline bTB + autumn \& winter & & 2.955 & 1.948 & & & 1.745 & 1.001 \\
\hline SE & & 0.378 & 0.195 & & & 0.182 & $<0.001$ \\
\hline$P$-value & & 0.004 & 0.006 & & & 0.004 & $<0.001$ \\
\hline Spring \& summer & & 6.295 & 11.945 & 1.245 & 4.892 & 4.195 & 0.999 \\
\hline $\mathrm{SE}^{1}$ & & 0.478 & 0.279 & 0.311 & 0.669 & 0.367 & $<0.001$ \\
\hline$P$-value & & $<0.001$ & $<0.001$ & $<0.001$ & 0.017 & $<0.001$ & 0.004 \\
\hline $\mathrm{bTB}+$ spring $\&$ summer & 0.117 & & & 4.221 & & & \\
\hline SE & 0.329 & & & 0.737 & & & \\
\hline$P$-value & $<0.001$ & & & $<0.001$ & & & \\
\hline
\end{tabular}


Table 3. Model structure, coefficient of determination, corresponding Akaike's Information Criterion, $\left(\mathrm{AIC}_{c}\right)$, and Akaike weight ( $w_{i}$; Burnham and Anderson 2002) for the top 3 models per category of interaction probabilities for space-sharing coyotes in Crawford and Oscoda counties, northeastern Michigan, USA 2001-2003.

\begin{tabular}{|c|c|c|c|}
\hline Model structure & $R^{2}$ & $\mathrm{AIC}_{c}$ & $w_{i}$ \\
\hline \multicolumn{4}{|l|}{ Full model—family groups included } \\
\hline $\begin{array}{l}\left.\text { 1. } \beta_{0}+\beta_{1}\left(\mathrm{MSD}^{\mathrm{a}} \text { timber cut }\right)-\beta_{2} \text { (group type }\right)+\beta_{3}(\mathrm{M}-\mathrm{M} \text { pair }) \\
\left.\left.\text { 2. } \beta_{0}+\beta_{1}(\mathrm{MSD} \text { timber cut })-\beta_{2} \text { (MSD conifer }\right)+\beta_{3} \text { (group type }\right) \\
\left.\text { 3. } \beta_{0}+\beta_{1}(\mathrm{MSD} \text { timber cut })-\beta_{2}(\mathrm{MSD} \text { conifer })+\beta_{3}(\mathrm{MSD} \text { wetland })-\beta_{4} \text { (group type }\right)-\beta_{5}(\mathrm{~F}-\mathrm{M} \text { pair })\end{array}$ & $\begin{array}{l}0.65 \\
0.56 \\
0.58\end{array}$ & $\begin{array}{l}-130.72 \\
-128.58 \\
-127.89\end{array}$ & $\begin{array}{l}0.560 \\
0.193 \\
0.136\end{array}$ \\
\hline \multicolumn{4}{|l|}{ Reduced model—family groups excluded } \\
\hline $\begin{array}{l}\text { 1. } \beta_{0}+\beta_{1}(\text { MSD timber cut })+\beta_{2}(\mathrm{M}-\mathrm{M} \text { pair }) \\
\text { 2. } \beta_{0}+\beta_{1}(\text { MSD timber cut })-\beta_{2}(\text { MSD conifer })+\beta_{3}(\text { MSD wetland })+\beta_{4}(\mathrm{M}-\mathrm{M} \text { pair }) \\
\text { 3. } \beta_{0}+\beta_{1}(\text { MSD timber cut })-\beta_{2}(\text { MSD conifer })+\beta_{3}(\text { MSD wetland })\end{array}$ & $\begin{array}{l}0.50 \\
0.55 \\
0.49\end{array}$ & $\begin{array}{l}-114.39 \\
-113.77 \\
-111.96\end{array}$ & $\begin{array}{l}0.393 \\
0.287 \\
0.116\end{array}$ \\
\hline $\begin{array}{l}\text { Reduced model-bTB }+ \text { area } \\
\text { 1. } \beta_{0}+\beta_{1}(\mathrm{MSD} \text { timber cut })+\beta_{2}(\mathrm{M}-\mathrm{M} \text { pair }) \\
\text { 2. } \beta_{0}+\beta_{1}(\mathrm{MSD} \text { timber cut })+\beta_{2}(\mathrm{MSD} \text { conifer })+\beta_{3}(\mathrm{MSD} \text { wetland }) \\
\text { 3. } \beta_{0}+\beta_{1}(\mathrm{MSD} \text { timber cut })\end{array}$ & $\begin{array}{l}0.58 \\
0.32 \\
0.32\end{array}$ & $\begin{array}{l}-71.32 \\
-63.10 \\
-59.26\end{array}$ & $\begin{array}{l}0.979 \\
0.016 \\
0.002\end{array}$ \\
\hline
\end{tabular}

${ }^{\mathrm{a}} \mathrm{MSD}=$ mean-squared difference.

1.839), and timber management patches $(\beta=2.480)$ decreased with increasing distance from roads $(\beta=$ -0.001 ; Table 2). Four spring and summer OZs fell completely within the bTB + area, and probability of coyote occurrence increased in wetlands $(\beta=3.187)$ and decreased in mixed forest $(\beta=-2.146$; Table 2$)$.

\section{Influence of Disease Prevalence and Landscape Attributes on Spatial Ecology}

Home-range size varied greatly (model: $F_{4,29}=3.80, P=$ 0.01 ; range $\left.=3.78-62.25 \mathrm{~km}^{2}\right)$ between seasons $\left(F_{1,32}=\right.$ $10.35, P=0.003)$; home ranges in autumn and winter $(\bar{x}=$ $\left.33.58 \mathrm{~km}^{2}, 95 \% \mathrm{CI}=23.59-43.57 \mathrm{~km}^{2}\right)$ were substantially larger than in spring and summer $\left(\bar{x}=14.25 \mathrm{~km}^{2}, 95 \% \mathrm{CI}=\right.$ $\left.9.54-18.96 \mathrm{~km}^{2}\right)$. Home-range size did not vary relative to sex $\left(F_{1,32}=0.39, P=0.54\right)$ or bTB prevalence $\left(F_{1,32}=0.86\right.$, $P=0.36)$ and no interactions were significant. A similar pattern was evident for core areas (model: $F_{4,29}=4.80, P=$ 0.004 ; range $=0.49-13.51 \mathrm{~km}^{2}$ ); size was greater in autumn and winter $\left(F_{1,32}=15.12, P=<0.001\right)$ but did not vary relative to sex $\left(F_{1,32}=0.26, P=0.62\right)$ or bTB prevalence $\left(F_{1,32}=2.77, P=0.11\right)$. By contrast, the extent of homerange overlap was consistent (model: $F_{8,32}=0.82, P=0.59$; autumn-winter $\bar{x}=0.27 \%, 95 \% \mathrm{CI}=0.17-0.37 \%$; springsummer $\bar{x}=0.21 \%, 95 \% \mathrm{CI}=0.10-0.32 \%)$ and $\mathrm{did}$ not vary relative to season $\left(F_{1,39}=0.01, P=0.97\right)$, pair type $\left(F_{2,38}=1.50, P=0.24\right)$, or bTB prevalence $\left(F_{1,39}=1.69, P\right.$ $=0.20)$.

Four variables were retained in our best regression model of factors correlated with interaction probabilities $\left(P_{i j}\right)$ for all spatially overlapping coyote pairs (Table 3). Interaction probabilities were positively correlated with nearest-neighbor distance between wetland $(\beta=0.008)$ and timber management patches $(\beta=0.103)$ and were negatively correlated with distance between nearest-neighbor mixedforest patches $(\beta=-0.039)$. Interaction probabilities were also positively $(\beta=0.098)$ correlated with the sex of the interacting pair; $\mathrm{OZ}$ s of adjacent male-male coyotes had higher interaction probabilities than other combinations (Table 4). Although the analysis captured a substantial portion of variation $\left(R^{2}=0.55\right)$, partial regressions indicated that most of the variation could be attributed to the nearestneighbor distance between timber management patches $\left(r^{2}=0.42\right)$. When we censored overlapping pack members from the data (reduced-set models), only the nearestneighbor distance between timber management patches $(\beta=$ 0.094; Fig. 2) and male-male pairs $(\beta=0.109)$ were retained in the best model (Table 3 ). The reduced-set top-ranked model was only about 1.3 times as likely to be the best candidate as the second-ranked model (i.e., $\beta_{0}+\beta_{1}[\mathrm{MSD}$ timber management $-\beta_{2}[\mathrm{MSD}$ conifer $]+\beta_{3}[\mathrm{MSD}$ wetland $]+\beta_{4}[\mathrm{M}-\mathrm{M}]$; Table 3 ). However, despite model uncertainty, the retention of MSD timber cut and malemale pair variables in the top 2 candidate models supports their importance to interaction probabilities. For our reduced-set bTB model (comprised only of overlapping, nonfamilial pairs partially or completely within the bTB+ polygon), MSD of nearest-neighbor timber management patches (Fig. 3) and M-M pairs were the only variables retained $\left(R^{2}=0.38\right.$; Table 3$)$.

Table 4. Interaction probabilities $\left(P_{i j}\right)$ of coyote pairs by group type, season, and bovine tuberculosis (bTB) prevalence, Crawford and Oscoda counties, Michigan, USA 2001-2003. Higher probabilities reflect an increased likelihood of a spatial interaction within the overlap zone. We omitted group type by season by bTB prevalence categories from the table when a lack of sufficient data precluded calculation of a mean. We excluded breeding pairs from the analysis.

\begin{tabular}{cccccc}
\hline \multirow{2}{*}{$\begin{array}{c}\text { Pair } \\
\text { type }\end{array}$} & $\begin{array}{c}\text { Group } \\
\text { type }\end{array}$ & \multicolumn{1}{c}{ Season } & bTB & \multicolumn{2}{c}{$\boldsymbol{P}_{i j}$} \\
\cline { 5 - 6 } & prevalence & $\overline{\boldsymbol{x}}$ & SE \\
\hline \multirow{2}{*}{${\mathrm{F}-\mathrm{M}^{\mathrm{a}}}$} & family & autumn \& winter & positive & 0.667 & 0.103 \\
& adjacent & autumn \& winter & positive & 0.139 & 0.081 \\
& & & negative & 0.137 & 0.118 \\
$\mathrm{~N}-\mathrm{M}$ & family & spring \& summer & positive & 0.727 & 0.184 \\
& family & autumn \& winter & positive & 0.509 & 0.090 \\
& adjacent & autumn \& winter & positive & 0.309 & 0.133 \\
& & & negative & 0.179 & 0.071 \\
F-F & adjacent & spring \& summer & negative & 0.312 & 0.278 \\
& adjacent & autumn \& winter & positive & 0.052 & 0.043
\end{tabular}

${ }^{\mathrm{a}}$ Nonbreeding F-M pairs. 


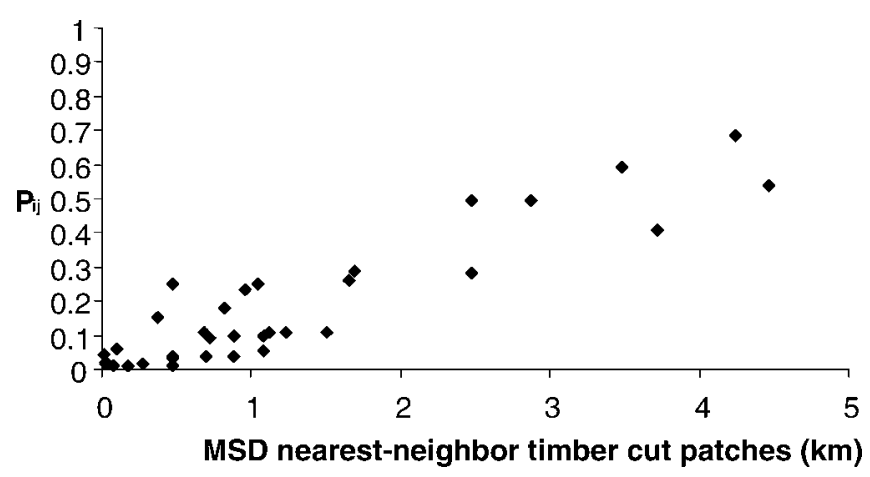

Figure 2. Interaction probabilities $\left(P_{i j}\right)$ of adjacent overlapping coyote pairs (reduced model) plotted against the mean-squared difference (MSD) of nearest-neighbor timber cut patches in Crawford and Oscoda counties in the northeastern Lower Peninsula of Michigan, USA, 2001-2003.

\section{DISCUSSION}

Previous work has demonstrated that coyotes appear to meet 2 of 3 (i.e., reasonable sampling effort, direct route of infection, and high spatial correlation on disease prevalence between host and sentinel) criteria for an effective sentinel species; coyotes facilitate detection of disease prevalence with reasonable sampling effort and become infected via direct interaction with the host species (Bruning-Fann et al. 2001, Payeur et al. 2002). The former is particularly important because, although extensive surveillance has established that bTB infection might be chronic in a core area of northeastern Michigan, disease prevalence in whitetailed deer is relatively low and, thus, hard to detect. For example, over a 10-year period (1995-2005) only 50 of 10,696 white-tailed deer sampled in Oscoda and Crawford counties were found to be $\mathrm{bTB}+$, resulting in a prevalence rate of $0.46 \%$ (MDNR 2005). By comparison, over the same period of time, the prevalence of bTB infection in coyotes for the bTB-endemic core area (deer management unit 452 in Alcona, Alpena, Montmorency, and Oscoda counties) was $25 \%$ (37 of 165 coyotes tested bTB+). Clearly, enhanced prevalence of infection coupled with reduced sampling effort make coyotes a viable biosurveillant agent for bTB-infected white-tailed deer. However, we must note that alternative modes of pathogen acquisition by coyotes remain speculative (Bruning-Fann et al. 2001) because no work has been done to determine direct or indirect infection rates. Circumstantial evidence, such as detection of Mycobacterium bovis in gastrointestinal lymph nodes, exists, supporting the notion that tissue ingestion may be a primary mode of pathogen acquisition. However, until rigorous work is conducted, arrant conclusions about the modes of bTB infection in coyotes could lead to sophistic inferences about the spatial epidemiology of bTB.

With regards to the third criterion, our work indicates that variation in coyote home-range size, in concert with likelihood of overlap between adjacent home ranges, may confound attempts to spatially correlate the incidence of disease in the sentinel and host species at a fine scale. That is, coyotes sampled from adjacent overlapping home ranges may test $\mathrm{bTB}+$, but when adjacent home ranges are sizable,

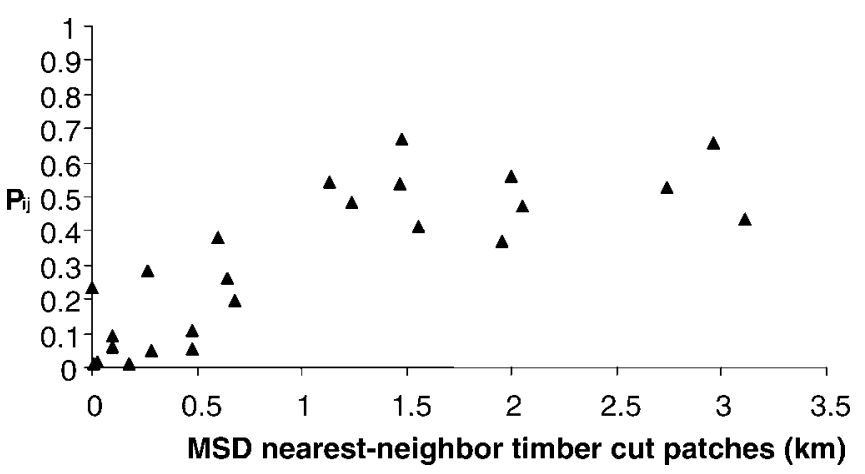

Figure 3. Interaction probabilities $\left(P_{i j}\right)$ of adjacent overlapping coyote pairs partially or completely within the bovine tuberculosis (bTB) prevalence zone (reduced, bTB-positive) plotted against the mean-squared difference (MSD) of nearest-neighbor timber cut patches in Crawford and Oscoda counties in the northeastern Lower Peninsula of Michigan, USA, 2001-2003.

residual error will be large and variance inflated (Neter et al. 1996). Thus we posit that the OZ between adjacent home ranges is more appropriate to use in attempts to spatially correlate disease prevalence in coyotes and white-tailed deer. The OZ, as a focal attractor, offers the additional benefit of concentrating spatial interaction between adjacent groups in a relatively small area. Presumably, OZs are attractors because they are resource rich. If the primary resource is carrion subsidies from winter- or hunter-killed white-tailed deer, then the potential for spatial interaction between adjacent coyote groups should be great (Gese et al. 1996, Wilmers et al. 2003, Atwood 2006). Spatial interaction between adjacent groups can lead to scramble competition for $\mathrm{OZ}$ resources, and inter-group agonism has been found to increase the likelihood of pathogen acquisition in badgers (Meles meles; Clifton-Hadley et al. 1993). However, it should be noted that the extent to which interspecific interactions mediate pathogen acquisition will largely depend on the focal-species' life history. For example, badgers are fossorial, highly social, and communal during whelping; these behaviors facilitate infection via inhalation of aerosolized bacilli (Cheeseman et al. 1988) and provide opportunity for badgers to serve as a primary host for maintaining $M$. bovis. By contrast, the likelihood of a similar route of infection and host maintenance should be reduced in coyotes as they use dens seasonally and are territorial rather than communal. The extent to which infection in coyotes is mediated by direct interaction with deer or through social contact with other coyotes remains unknown and is beyond the scope of our study. However, until proven otherwise, we must assume that the primary route of pathogen acquisition by coyotes is through ingestion of tissues from infected white-tailed deer and the contribution of agonistic interactions in facilitating infection is subordinate. Rigorous research on direct and indirect modes of Mycobacterium bovis acquisition is warranted.

The efficacy of coyotes as a sentinel species is based, in large part, on the corollary that scavenging behavior enhances the likelihood of coyotes ingesting tissue from infected deer. This logical extension is not without foundation. For example, grizzly bears (Ursus arctos) and wolves (Canis lupus) in 
Yellowstone National Park (YNP) demonstrated ephemeral changes in spatial and foraging behaviors coincident with ungulate hunting seasons; both species exploited space characterized by high levels of hunting activity, putatively to take advantage of foraging opportunities provided by gut piles and crippled ungulates (Ruth et al. 2003). Coyotes in northern Michigan may have been behaving in a similar manner at both the home range and $\mathrm{OZ}$ scales. For example, differences in seasonal home-range areas might be attributed to declines in spring-summer home ranges resulting from demands of puprearing (Andelt et al. 1979), but they also could result from expansion in autumn-winter to increase the likelihood of encountering hunter-provisioned carrion. In the latter construct, home-range expansions need not necessitate contractions by adjacent social groups. Indeed, there is some evidence that, like other canids (e.g., Macdonald et al. 1999, Baker et al. 2000), coyotes may not be obligately territorial and will tolerate spatial overlap by adjacent packs (Atwood and Weeks 2003). Our data do not explicitly provide evidence that autumn-winter home-range expansions occur in response to perceived hunting activity. Rather, our data do not discount that resource acquisition is a plausible scenario for expansions.

Seasonal resource-selection models were qualitatively similar at their respective scales, except OZs. Within home ranges coyote probability of occurrence was greatest in conifer, mixed-forest, and timber management patches regardless of season. Similar patterns were manifest for seasonal core-area RSF models; patch types selected by coyotes were similar between seasons. These patterns of seasonal resource selection suggest that home-range expansion was not directly habitat mediated. The retention of a consistent set of core-area RSF parameters and the resultant consistent covariance matrices allowed us to directly compare coefficients from autumnwinter and spring-summer models (Hosmer and Lemeshow 2000) and, thereby, assess the relative importance of those parameters based on season. For example, autumn-winter use of conifer, wetland, and mixed-forest patches increased by $45 \%, 39 \%$, and $20 \%$ respectively, relative to use in springsummer. Thus, although selection of patch types was similar, intensity of exploitation differed substantially. This would indicate that coyotes were not compelled to seek different habitat types relative to season but rather varied the intensity of patch exploitation accordingly. Within OZs there were no salient patterns of resource selection relative to season. However, similar to home ranges and core areas, coyote occurrence increased in timber management patches in the autumn-winter season for OZs partially or completely within the $\mathrm{bTB}+$ polygon. The selection for timber management patches within the $\mathrm{OZ}$ is notable, particularly given that these patches are also used intensively in core areas. There are 2 possible explanations for the selection of timber management patches by coyotes: 1) food resources were more available or 2) structural complexity offered refugia from hunters (Atwood et al. 2004). Relative to the former, Fisher and Wilkinson (2005) found that small mammals and ungulates were most abundant in timber stands for up to 10 years following cut-and-burn treatments. The increased abundance of food resources in regenerating timber management patches should provide impetus for coyotes to configure core areas and OZs around these patches. However, Young et al. (2006) found that coyotes did not immediately respond to burn treatments by reconfiguring core areas around burned habitat.

An interesting, and certainly not ancillary, finding was percent home-range overlap did not increase concomitant with home-range expansions. Percent overlap was similar between seasons; however, it is important to note that we sampled fewer overlapping home ranges in the springsummer season. Lack of a seasonal difference in percent overlap may reflect either a general cultural tolerance of adjacent social groups (Young et al. 2006) or sex-biased territorial defense behavior (Gese 2001). Our regression analysis of interaction probabilities suggests both scenarios are plausible though the effect strength of each as a contributing factor may differ. For example, relative to pair type, interaction probabilities were highest among adjacent malemale pairs; males are most likely to engage in the maintenance of territorial borders (Gese 2001). However, based on partial regressions, interaction probabilities were most strongly influenced by the MSD of nearest-neighbor timber management patches. Thus, although both social and landscape factors appear to be contributing to the probability of spatial interaction, the landscape effect is overwhelming the social effect.

Using behavioral and landscape variables to estimate the probability of a spatial interaction is germane when both behavior and habitat are suspected to be complicit in modulating the spatial dispersion of a pathogen. Determining the relative correlations of these variable types with interaction probabilities can help focus future efforts. Our finding that, in OZs, the MSD of nearest-neighbor timber management patches overwhelmed the effect of pair type is exemplary, and is a critical distinction to make. The importance of the dispersion of this patch type is further evidenced by the retention of the MSD of nearest-neighbor timber management patches in the top-ranked set of all model groups (i.e., full, reduced, reduced-bTB+; Table 3). Our results indicate 1) the probability of coyote occurrence within $\mathrm{bTB}+$ areas is elevated in timber management patches, 2) OZs appear to be configured around these patches, and 3) the spatial arrangement of these patches facilitates interaction. Based on these findings the spatial dispersion of timber management patches should be considered in future efforts to develop spatially explicit models of bTB dynamics. We caution it is not our intent to deemphasize the importance of social interaction in mediating pathogen acquisition. Rather we feel if goals are to develop predictive models on bTB transmission, then it may be much simpler to develop, parameterize, and validate habitat-based models as opposed to trying to collect data on rare events such as agonistic interactions within an $\mathrm{OZ}$.

\section{MANAGEMENT IMPLICATIONS}

Our analysis of coyote spatial and behavioral ecology relative to the distribution of bTB indicates the potential exists to 
employ coyotes as a sentinel to detect bTB prevalence at coarse spatial scales, such as townships or deer management units. At coarser scales, the large variance in home-range size and the attendant concern of poor spatial correlation between the incidence of disease in the sentinel and host species becomes irrelevant. We envision future efforts focused on the development of predictive models at these scales to identify areas where coyotes are likely to acquire bTB from white-tailed deer. Coarse-scale models of whitetailed deer habitat suitability exist (Felix et al. 2004) for northern Michigan and could be integrated with coyote resource-selection models to characterize the intensity of coyote patch selection in relation to suitability for deer. Once these patches are identified, sampling design for surveillance programs can be stratified so that effort is allocated proportional to predicted intensities of use. Modeling efforts can then be used as a foundation to predict the epidemiological ramifications of alterations in intensively managed forested landscapes.

\section{ACKNOWLEDGMENTS}

D. Lunning, R. Schanck, A. Adams, G. Rigney, P. Ryan, and other Wildlife Services employees aided in trapping and other field aspects of our study. T. Gidlewski, B. Thomsen, and J. Payeur of Veterinary Services contributed valuable expertise in the laboratory. J. Fischer, J. Young, D. Euler, and 2 anonymous reviewers provided helpful comments on an earlier version of this manuscript.

\section{LITERATURE CITED}

Altizer, S., C. L. Nunn, P. H. Thrall, J. L. Gittleman, J. Antonovics, A. A. Cunningham, A. P. Dobson, V. Ezenwa, K. E. Jones, A. B. Pedersen, M. Poss, and J. R. C. Pulliam. 2003. Spatial organization and parasite risk in mammals: integrating theory and empirical studies. Annual Review of Ecology, Evolution, and Systematics 34:517-547.

Andelt, W. F., D. P. Althoff, and P. S. Gipson. 1979. Movements of breeding coyotes with emphasis on den site relationships. Journal of Mammalogy 60:568-575.

Atwood, T. C. 2006. Behavioral interactions between coyotes, Canis latrans, and wolves, Canis lupus, at ungulate carcasses in southwest Montana. Western North American Naturalist 66:390-394.

Atwood, T. C., and H. P. Weeks, Jr. 2003. Spatial home-range overlap and temporal interaction in eastern coyotes: the influence of pair types and fragmentation. Canadian Journal of Zoology 81:1589-1597.

Atwood, T. C., H. P. Weeks, Jr., and T. M. Gehring. 2004. Spatial ecology of coyotes along a suburban-to-rural gradient. Journal of Wildlife Management 68:1000-1009.

Baker, P. J., S. M. Funk, S. Harris, and P. C. L. White. 2000. Flexible spatial organization of urban foxes, Vulpes vulpes, before and during an outbreak of sarcoptic mange. Animal Behavior 59:127-146.

Bruning-Fann, C. S., S. M. Schmitt, S. D. Fitzgerald, J. S. Fierke, P. D. Friedrich, J. B. Kaneene, K. A. Clarke, K. L. Butler, J. B. Payeur, D. L. Whipple, T. M. Cooley, J. M. Miller, and D. P. Muzo. 2001. Bovine tuberculosis in free-ranging carnivores from Michigan. Journal of Wildlife Diseases 37:58-64.

Burnham, K. P., and D. R. Anderson. 2002. Model selection and multimodel inference: a practical information-theoretic approach. Second edition. Springer-Verlag, New York, New York, USA.

Cheeseman, C. L., and P. J. Mallinson. 1981. Behavior of badgers (Meles meles) infected with bovine tuberculosis. Journal of Zoology, London, 197:289-292.

Cheeseman, C. L., J. W. Wilesmith, F. A. Stuart, and P. J. Mallinson.
1988. Dynamics of tuberculosis in a naturally infected badger population. Mammal Review 18:61-72.

Cleaveland, S., M. K. Laurenson, and L. H. Taylor. 2001. Diseases of humans and their domestic mammals: pathogen characteristics, host range and the risk of emergence. Philosophical Transactions of the Royal Society of London, Series B, Biological Sciences 356:991-999.

Clifton-Hadley, R. S., J. W. Wilesmith, and F. A. Stuart. 1993. Mycobacterium bovis in the European badger (Meles meles): epidemiological findings in tuberculous badgers from a naturally infected population. Epidemiology and Infection 111:9-19.

Conner, M. M., and M. W. Miller. 2004. Movement patterns and spatial epidemiology of a prion disease in mule deer population units. Ecological Applications 14:1870-1881.

Crooks, K., and M. E. Soule. 1999. Mesopredator release and avifaunal extinctions in a fragmented system. Nature 400:563-566.

Cully, J. F., Jr., and E. S. Williams. 2001. Interspecific comparisons of sylvatic plague in prairie dogs. Journal of Mammalogy 82:894-905.

Delahay, R. J., S. Langton, G. C. Smith, R. S. Clifton-Hadley, and C. L. Cheeseman. 2000. The spatio-temporal distribution of Mycobacterium bovis (bovine tuberculosis) infection in a high density badger population. Journal of Animal Ecology 69:428-441.

de Villiers, M. S., P. R. K. Richardson, and A. S. van Jaarsveld. 2003. Patterns of coalition formation and spatial association in a social carnivore, the African wild dog (Lycaon pictus). Journal of Zoology, London 260:377-389.

Dobson, A. P., and J. Foufopoulos. 2001. Emerging infectious pathogens of wildlife. Philosophical Transactions of the Royal Society of London, Series B, Biological Sciences 356:1001-1012.

Felix, A. B., H. Campa, III, K. F. Millenbah, S. R. Winterstein, and W. E. Moritz. 2004. Development of landscape-scale habitat-potential models for forest wildlife planning and management. Wildlife Society Bulletin 32:795-806.

Fisher, J. T., and L. Wilkinson. 2005. The response of mammals to forest fire and timber harvest in the North American boreal forest. Mammal Review 35:51-81.

Francis, J. 1958. Tuberculosis in animals and man. Cassell, London, United Kingdom.

Garnett, B. T., R. J. Delahay, and T. J. Roper. 2005. Ranging behaviour of European badgers (Meles meles) in relation bovine (Mycobacterium bovis) tuberculosis infection. Applied Animal Behaviour Science 94:331-340.

Gese, E. M. 2001. Territorial defense by coyotes (Canis latrans) in Yellowstone National Park, Wyoming: who, how, where, when, and why. Canadian Journal of Zoology 79:980-987.

Gese, E. M., R. L. Ruff, and R. L. Crabtree. 1996. Social and nutritional factors influencing the dispersal of resident coyotes. Animal Behaviour 52:1025-1043.

Hess, G. R., S. E. Randolph, P. Arneberg, C. Chemimi, C. Furlanello, J. Harwood, M. G. Roberts, and J. Swinton. 2002. Spatial aspects of disease dynamics. Pages 102-118 in P. J. Hudson, A. Rizzoli, B. T. Grenfell, H. Heesterbeek, and A. P. Dobson, editors. The ecology of wildlife diseases. Oxford University Press, Oxford, United Kingdom.

Holekamp, K. E., S. M. Cooper, C. I. Katona, N. A. Berry, L. G. Frank, and L. Smale. 1997. Patterns of association between female spotted hyenas (Crocuta crocuta). Journal of Mammalogy 78:55-64.

Hosmer, D. W., and S. Lemeshow. 2000. Applied logistic regression. John Wiley \& Sons, Hoboken, New Jersey, USA.

Laurance, W. F., K. R. McDonald, and R. Speare. 1996. Epidemic disease and the catastrophic decline of Australian rain forest frogs. Conservation Biology 10:406-413.

Lee, J. E., G. C. White, R. A. Garrott, R. M. Bartmann, and A. W. Allredge. 1985. Assessing the accuracy of a radiotelemetry system for estimating mule deer locations. Journal of Wildlife Management 49:658663.

Macdonald, D. W., O. Courtenay, S. Forbes, and F. Mathews. 1999. The red fox (Vulpes vulpes) in Saudi Arabia: loose knit groupings in the absence of territoriality. Journal of Zoology, London 249:383-391.

Manly, B. F. J., L. L. McDonald, D. L. Thomas, T. L. McDonald, and W. P. Erickson. 2002. Resource selection by animals: statistical design and analysis for field studies. Kluwer Academic, Norwell, Massachusetts, USA

McCallum, H., N. Barlow, and J. Hone. 2001. How should pathogen transmission be modeled? Trends in Ecology and Evolution 16:295-300. 
McCallum, H., and A. P. Dobson. 2002. Disease, habitat fragmentation, and conservation. Proceedings of the Royal Society, Series B, Biological Sciences 269:2041-2049.

Michigan Department of Natural Resources [MDNR]. 2005. Michigan bovine tuberculosis eradication project: activities report and conference proceedings. Michigan Department of Natural Resources, Lansing, USA.

Mollison, D., and S. A. Levin. 1995. Spatial dynamics of parasitism. Pages 384-398 in A. P. Dobson and B. Grenfell, editors. Ecology of infectious diseases in natural populations. Cambridge University Press, United Kingdom.

Neter, J., M. H. Kutner, C. J. Nachtsheim, and W. Wasserman. 1996. Applied linear statistical models. McGraw-Hill, Boston, Massachusetts, USA.

Payeur, J. B., S. Church, L. Mosher, B. Robinson-Dunn, S. Schmitt, and D. Whipple. 2002. Bovine tuberculosis in Michigan wildlife. New York Academy of Sciences 969:259-261.

Pfeiffer, D. U., and M. Hugh-Jones. 2002. Geographical information systems as a tool in epidemiological assessment and wildlife disease management. Scientific and Technical Review of the Office of International des Epizooties 21:91-102.

Rhodes, C. J., R. P. D. Atkinson, R. M. Anderson, and D. W. Macdonald. 1998. Rabies in Zimbabwe: reservoir dogs and the implications for disease control. Philosophical Transactions of the Royal Society of London, Series B, Biological Sciences 353:999-1010.

Rogers, L. M., R. J. Delahay, C. L. Cheeseman, S. Langton, G. C. Smith, and R. S. Clifton-Hadley. 1998. Movement of badgers (Meles meles) in a high density population: individual, population, and disease effects. Proceedings of the Royal Society of London, Series B 265:1-8.

Ruth, T. K., D. W. Smith, M. A. Haroldson, P. C. Buotte, C. C. Schwartz, H. B. Quigley, S. Cherry, K. M. Murphy, D. Tyers, and K. Frey. 2003. Large-carnivore response to recreational big-game hunting along the Yellowstone National Park and Absaroka-Beartooth Wilderness boundary. Wildlife Society Bulletin 31:1150-1161.

Schmitt, S. M., S. D. Fitzgerald, T. M. Cooley, C. S. Bruning-Fann, L. Sullivan, D. Berry, T. Carlson, R. B. Minnis, J. B. Payeur, and J. Sikarskie. 1997. Bovine tuberculosis in free-ranging white-tailed deer in Michigan. Journal of Wildlife Diseases 33:749-758.

Schrag, S. J., and P. Wiener. 1995. Emerging infectious disease: what are the relative roles of ecology and evolution? Trends in Ecology and Evolution 10:319-324.

Seaman, D. E., J. J. Millspaugh, B. J. Kernohan, G. C. Brundige, K. J. Raedeke, and R. A. Gitzen. 1999. Effects of sample size on kernel home range estimates. Journal of Wildlife Management 63:739-747.

Shivik, J. A., and E. M. Gese. 2000. Territorial significance of home range estimators for coyotes. Wildlife Society Bulletin 28:940-946.

Smith, D. L., B. Lucey, L. A. Waller, J. E. Childs, and L. A. Real. 2002. Predicting the spatial dynamics of rabies epidemics on heterogeneous landscapes. Proceedings of the National Academy of Science 99:36683672.

Smith, G. C., M. S. Richards, R. S. Clifton-Hadley, and C. L. Cheeseman. 1995. Modelling bovine tuberculosis in badgers in England: preliminary results. Mammalia 59:639-650.

Taylor, L. H., S. Latham, and M. E. J. Woolhouse. 2001. Risk factors for human disease emergence. Philosophical Transactions of the Royal Society of London, Series B, Biological Sciences 356:983-990.

Theobald, D. M. 2003. Targeting conservation action through assessment of protection and exurban threats. Conservation Biology 17:1624-1637.

Turner, M. G. 1989. Landscape ecology: the effect of pattern on process. Annual Review of Ecology and Systematics 20:171-197.

Tuyttens, F. A. M., R. J. Delahay, D. W. Macdonald, C. L. Cheeseman, B. Long, and C. A. Donnelly. 2000. Spatial perturbation caused by a badger (Meles meles) culling operation: implications for the function of territoriality and the control of bovine tuberculosis (Mycobacterium bovis). Journal of Animal Ecology 69:815-828.

White, G. C., and R. A. Garrott. 1990. Analysis of wildlife radio-tracking data. Academic Press, New York, New York, USA.

White, P. C. L., and S. Harris. 1995. Bovine tuberculosis in badger (Meles meles) populations in southwest England: an assessment of past, present, and possible future control strategies using simulation modeling. Philosophical Transactions of the Royal Society of London, Series B, Biological Sciences 349:415-432.

Wiens, J. A., J. T. Rotenberry, and B. Vanhorne. 1986. A lesson in the limitations of field experiments: shrubsteppe birds and habitat alteration. Ecology 67:365-376.

Wilmers, C. C., D. R. Stahler, R. L. Crabtree, D. W. Smith, and W. M. Getz. 2003. Resource dispersion and consumer dominance: scavenging at wolf- and hunter-killed carcasses in Greater Yellowstone, USA. Ecology Letters 6:996-1003.

Woodroffe, R., C. A. Donnelly, D. R. Cox, F. J. Bourne, C. L. Cheeseman, R. J. Delahay, G. Gettinby, J. P. McInerney, and W. I. Morrison. 2006. Effects of culling on badger Meles meles spatial organization: implications for the control of bovine tuberculosis. Journal of Applied Ecology 43:110

Woolhouse, M. E. J., and S. Gowtage-Sequeria. 2005. Host range and emerging and re-emerging pathogens. Emerging Infectious Diseases 11: 1842-1847.

Young, J. K., W. F. Andelt, P. A. Terletzky, and J. A. Shivik. 2006. A comparison of coyote ecology after 25 years: 1978 versus 2003. Canadian Journal of Zoology 84:573-582.

Zar, J. H. 1999. Biostastistical analysis. Fourth edition. Prentice Hall, Upper Saddle River, New Jersey, USA.

Associate Editor: Euler. 